\title{
Removal of a Bronchial Foreign Body by Bronchoscopic Cryotherapy: A Case Study
}

\author{
Hyoyeon Kim \\ Gwanghyun Byun \\ Sang Joon Lee \\ Seung Hoon Woo
}

Department of Otorhinolaryngology-Head and Neck Surgery, Dankook University College of Medicine, Cheonan, Korea
Received August 24, 2020

Accepted November 4, 2020

\section{Correspondence}

Seung Hoon Woo

Department of Otorhinolaryngology-Head and Neck Surgery, Dankook University College of Medicine, 119 Dandae-ro, Dongnam-gu,

Cheonan 31116, Korea

Tel.: +82-41-550-1781

Fax: +82-41-550-7837

E-mail: lesabyahanmail.net

(C) Korean Society for Laser Medicine and Surgery

(c) This is an open access article distributed under the terms of the Creative Commons Attribution NonCommercial License (http://creativecommons.org/ licenses/by-nc/4.0) which permits unrestricted noncommercial use, distribution, and reproduction in any medium, provided the original work is properly cited.
A foreign body in the airway can be a potentially life-threatening event. The diagnosis and treatment of foreign bodies in the airway are a challenge for otolaryngologists. Despite the improvements in medical care and public awareness, approximately 3,000 deaths occur each year from foreign body aspiration. A high degree of vigilance is required to ensure prompt treatment and avoid the complications of foreign body aspiration. The author encountered a case of a 77-year-old female patient who had aspirated an unknown foreign body that was fixed in her main bronchus. An initial attempt was made to remove it with a flexible bronchoscope but failed due to the patient's hypoxemic state during the procedure. Under general anesthesia, a rigid bronchoscopic examination was performed, but it was difficult to approach the object due to the bronchus curvature. Instead, a cryotherapy instrument of bronchoscopy was applied. The foreign body was frozen and removed to the carina, where a laryngoscope and laryngeal forceps were used to remove it.

\section{Key words}

Cryotherapy; Foreign body; Bronchoscope; Laryngoscope 


\section{INTRODUCTION}

Adult foreign body aspiration (FBA) typically presents with a choking event followed by persistent coughing but not uncommonly, it can mimic more chronic diseases such as chronic obstructive pulmonary disease, asthma, and obstructive pneumonia when the initial event goes unnoticed (for example in elderly patient with an altered mental status). ${ }^{1}$ When an accurate diagnosis is not established immediately, entrenched foreign bodies (FBs) may lead to recurrent pneumonias, bronchiectasis, recurrent hemoptysis, pneumothorax, lung abscesses, pneumomediastinum and other complications. ${ }^{2,3}$ Extraction of aspirated FBs should be undertaken as soon as possible in order to alleviate acute symptoms and prevent long term complications. ${ }^{4}$

This is a report of a 77-year-old female, who initially manifested dyspnea, fever and sputum. These are common symptoms of pneumonia but she turned out to have a FB in her left main bronchus. While examining and attempting to remove it, we applied several steps to approach it and in the end, we carefully removed it through by flexible bronchoscopy, cryoprobe, and laryngeal forceps.

\section{CASE REPORT}

A 77-year-old woman was admitted to our emergency room with dyspnea. She had a history of marginal resection and colostomy due to sigmoid perforation in 2010, a takedown operation for colostomy repair in 2011, multi infarct dementia from 2014, and most recently, percutaneous coronary intervention at the mid left anterior descending coronary artery and asthma aggravation and pneumonia, in August, 2019. After discharge, she remained on in bed rest with her respiration assisted by oxygen (2 L/min) via nasal prong.

A week before, she had a fever up to $38.5^{\circ} \mathrm{C}$ and intermittent thick sputum. These symptoms worsened and eventually she had dyspnea. On examination, dyspnea was aggravated, and a steady increase of oxygen was needed to maintain saturation. Chest X-rays (Fig. 1A, B) and computed tomography (CT) scan (Fig. 1C, D) taken after admission showed signs of left pneumonia, but her
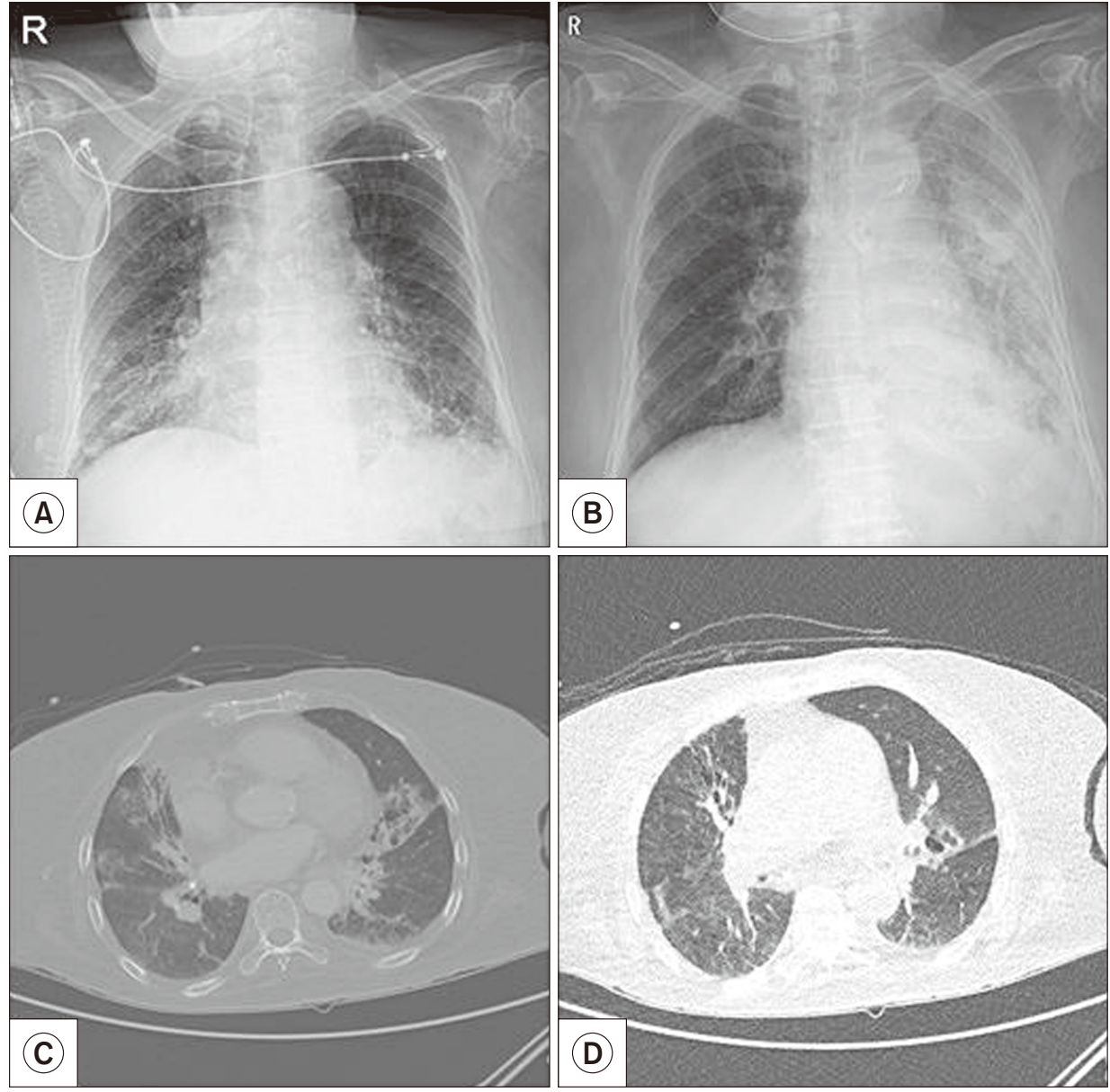

Fig. 1. Simple chest X-ray, anteriorposterior view, (A) Initial X-ray on Admission day and (B) Diffuse pneumonic infiltration in left after 2 days of admission. Chest computed tomography (CT), axial view showing ground-glass opacity at multiple sites as signs of pneumonia, unspecified, (C) CT obtained with mediastinal window setting (D) CT obtained with lung window setting. 
symptoms did not improve even after changing intravenous antibiotics. She was moved to the intensive care unit from the general ward for close monitoring.

On the third day of admission, flexible bronchoscopy was done (Fig. 2A, B). A moderate amount of mucopurulent secretion was found in the right bronchial tree. Multifocal hyperemic edematous mucosal change was found in the right bronchial tree. We found a stone like FB at the orifice of left main bronchus, but failed to remove it, due to patient's immediate hypoxemic state $1 \mathrm{SpO2} 88 \%$, via HFNC FiO2 0.9) (Fig. 2C, D). She was referred to the otorhinolaryngology department for exploration and removal of the FB.

Under general anesthesia, a rigid bronchoscopic exam was done. There was FB material and pus at the left main bronchus as was seen in at previous flexible bronchoscopic exam (Fig. 3A), but we found it difficult to approach the FB due to the bronchus curvature. We then applied a flexible bronchoscope to fit in the bronchial curvature. Using a cryoprobe guided by the pulmonologist, an adequate approach to the lower tracheal level was achieved and the tip of the cryoprobe touched the surface of the FB to freeze it (Fig. 3B). The FB material was carefully pulled out and disconnected from the cryoprobe at the carina. Removal was completed with using laryngeal forceps (Fig. 3C, D).

Four days later, the patient's vital signs were stabilized and follow-up rigid bronchoscopy was done. Multifocal hyperemic edematous mucosal change with erosion was found in the right bronchial tree. Similarly, multifocal hyperemic mucosal change was found in the left bronchial tree, as a sign of acute bronchitis. There were no other complications.

\section{DISCUSSION}

Aspiration of a FB is a potentially life-threatening emergency and $75 \%$ of cases occur in children younger than 3 years of age. ${ }^{5}$ FBA does happen in adults and elderly people as well.

Most adult patients with FBA have obvious risk factors for aspiration including neurological deficits with swallowing difficulties or altered mental status, neuromuscular disease, intoxication, or an iatrogenic cause. FB aspiration
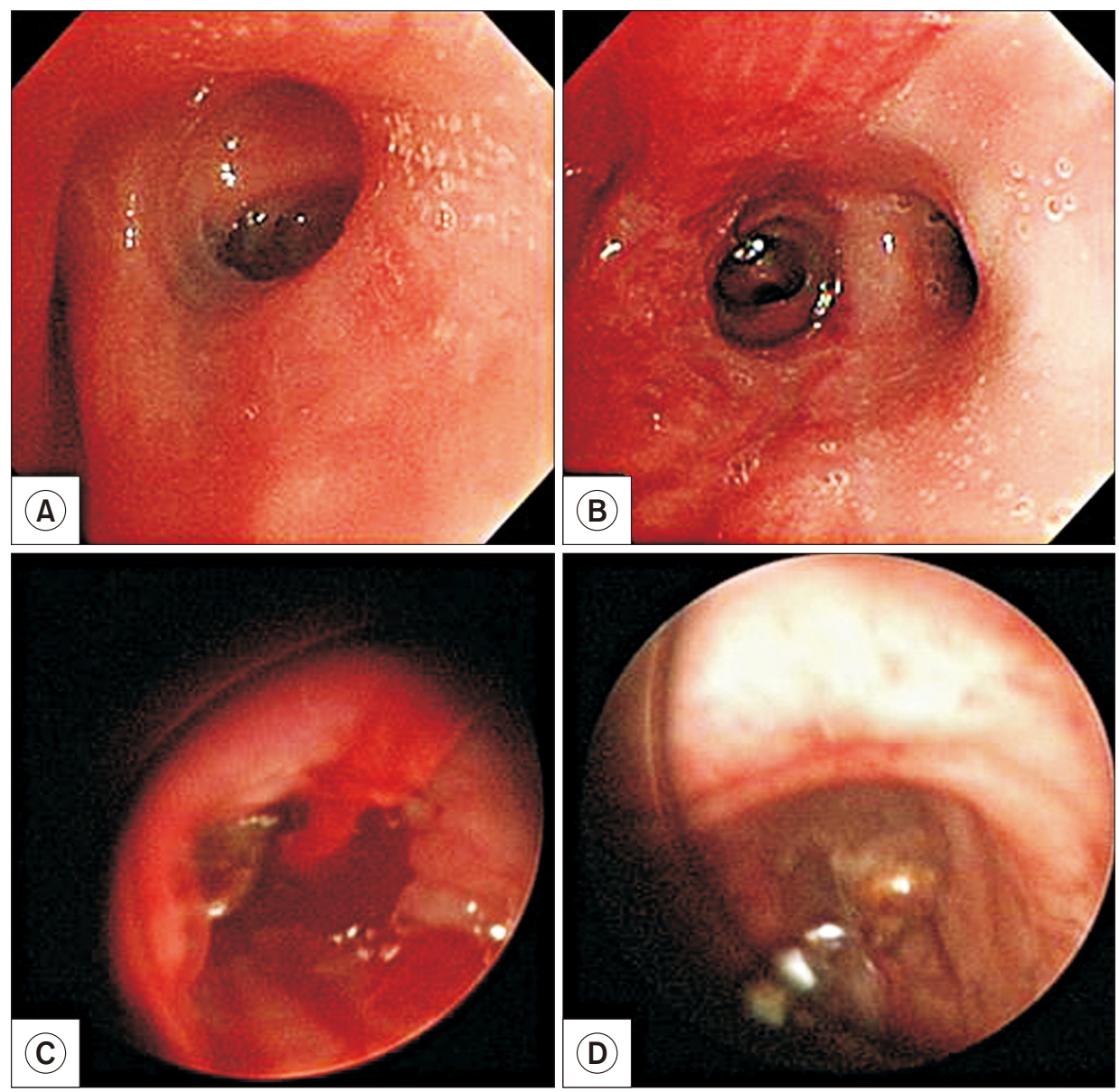

Fig. 2. Bronchoscopy, (A) Mucopurulent secretion in the right bronchial tree, (B) Multifocal hyperemic edematous mucosal change in the right bronchial tree, partial exposure of foreign body (FB) fixed in the right bronchial tree Rigid bronchoscope, (C) Exposure of FB fixed in the right bronchial tree, (D) Trials of FB removal with laryngeal forcep. 


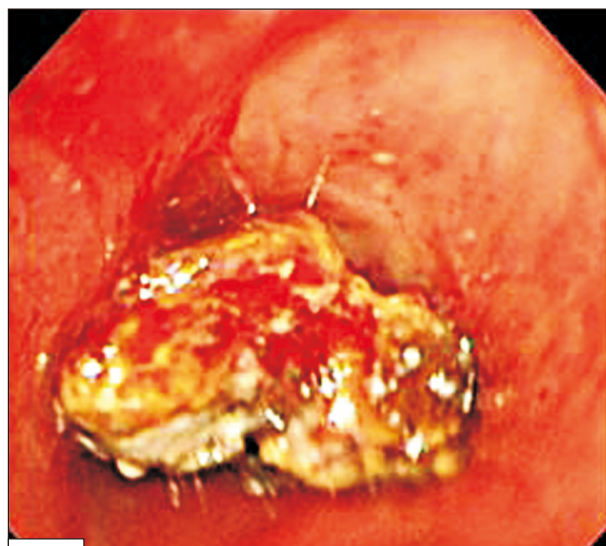

(A)

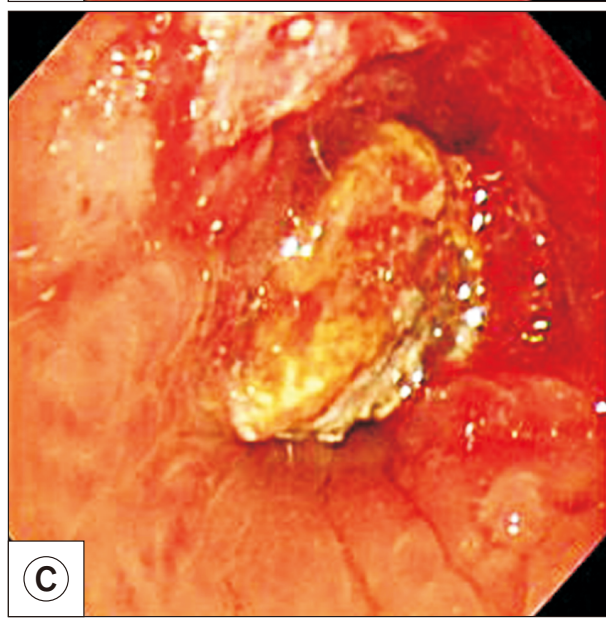

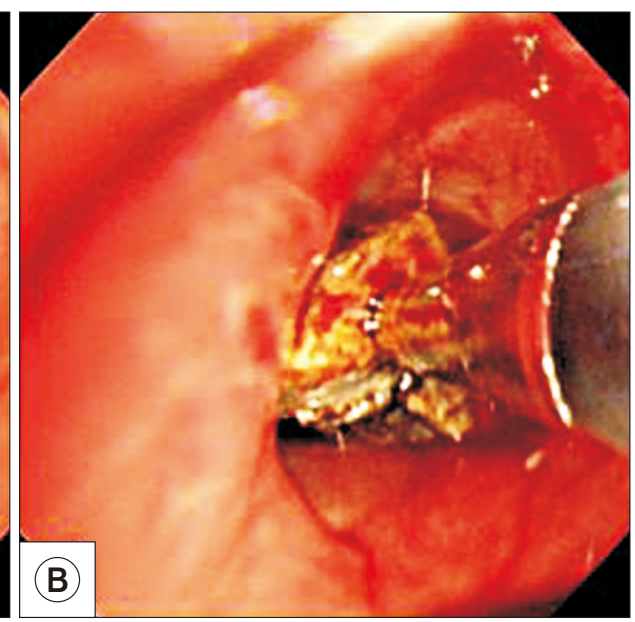

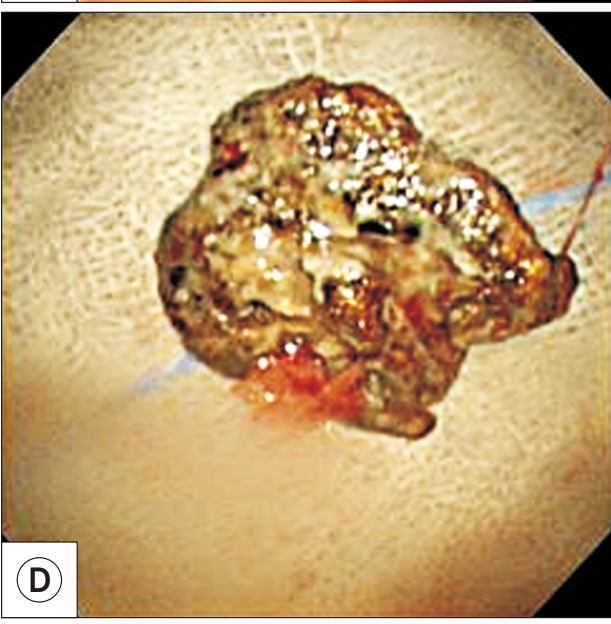

Fig. 3. Flexible bronchoscope and cryoprobe, (A) FB stuck at left bronchial tree, (B) Successful cryoadhesion of the probe and the surface of FB, (C) Detached FB from cryoprobe at carina, (D) Completely removed $\mathrm{FB}$, which later turned out to be an aspirated old dental metal filling material. risk appears to increase with age. latrogenic FB aspiration in adults is most commonly related to dental procedures requiring local anesthesia and supine positioning, and is also associated with tracheostomy care. ${ }^{6}$

After FBA occurs, the FB can settle into 3 anatomic sites, the larynx, trachea, or bronchus. Of aspirated foreign bodies, 80 to $90 \%$ become lodged in the bronchi. In adults, bronchial FBs tend to be lodged in the right main bronchus because of its lesser angle of convergence compared with the left bronchus and because of the location of the carina left of the midline. ${ }^{7}$ Larger objects tend to become lodged in the larynx or trachea. In adults approximately $40 \%$ of FBs are found in the left bronchial tree and only 5 to $11 \%$ remain in the trachea. ${ }^{8}$

For examination, standard posteroanterior and lateral chest radiographs should be obtained in all patients where FBA is suspected. Radiographs directly identify FB in only $25 \%$ of patients, because only a small proportion of objects such as coins, nails, teeth, and dental appliances are radiopaque. Nonetheless, chest radiographs demonstrate indirect findings of atelectasis, hyperinflation, or lobar consolidation in the majority of patients who have FBA.

Chest CT is more sensitive for identification of FBs, helps with procedural planning, and has become the gold standard of imaging studies when a FBA is suspected.

The most important aspect of successful FB extraction is pre-procedural planning, considering the characteristics of the FB, its size, location in the airway, and the patient's comorbid conditions. In general, rigid bronchoscopy is preferred in cases of acute respiratory distress, while flexible bronchoscopy allows for a more comprehensive airway survey and has an overall $90 \%$ success rate for retrieval. ${ }^{10,11}$ In our case, the use of the flexible cryoprobe was shown to be very effective, for removing $F B$, especially as the FB had an organic portion with significant granulation tissue around it. ${ }^{12-14}$ In this technique, the cryoprobe is advanced towards the FB through the working channel. After contact, the probe is activated to rapidly freeze the object and cause it to adhere to the cryoprobe tip. ${ }^{15,16}$ Once cryoadhesion has occurred, the object can be gently removed from the airway. Care must 
be taken not to touch the bronchial walls with the probe, as this can result in removal of bronchial tissue, bleeding, and rarely, airway perforation. The adherent ability of FBs is primarily based on their water content. ${ }^{10}$

After removal of the FB, it is imperative that the bronchoscopist performs a second airway survey for additional FBs and other side effects (such as granulation or bronchial stenosis. ${ }^{17-21}$

In summary, for patients with FBs in tricky positions in the trachea, a flexible cryoprobe can be an alternative way to remove them. We would like to report this rare case of using a cryoprobe for FB removal with the bibliography attached.

\section{CONFLICT OF INTEREST}

Seung Hoon Woo is the Editor-in-Chief of the journal but was not involved in the review process of this manuscript. Otherwise, there is no conflict of interest to declare.

\section{FUNDING}

None.

\section{REFERENCES}

1. Hewlett JC, Rickman OB, Lentz RJ, Prakash UB, Maldonado F. Foreign body aspiration in adult airways: therapeutic approach. J Thorac Dis 2017;9:3398-409.

2. Oliveira CF, Almeida JF, Troster EJ, Vaz FA. Complications of tracheobronchial foreign body aspiration in children: report of 5 cases and review of the literature. Rev Hosp Clin Fac Med Sao Paulo 2002;57:108-11.

3. Mun IK, Ju YR, Lee SJ, Woo SH. A case of bilateral tension pneumothorax after the successful CO2 laser-assisted removal of a bronchial foreign body in a child. Med Lasers 2020;9:65-70.

4. Cho JG, Park MW, Baek SK, Kwon SY, Jung KY, Woo JS. CO2 laser in the diagnosis and treatment of early cancer of the vocal fold. Med Lasers 2012;1:21-7.

5. Blanco Ramos M, Botana-Rial M, García-Fontán E, FernándezVillar A, Gallas Torreira M. Update in the extraction of airway foreign bodies in adults. J Thorac Dis 2016;8:3452-6.

6. Wolkove N, Kreisman H, Cohen C, Frank H. Occult foreignbody aspiration in adults. JAMA 1982;248:1350-2.
7. Wu TH, Cheng YL, Tzao C, Chang H, Hsieh CM, Lee SC. Longstanding tracheobronchial foreign body in an adult. Respir Care 2012;57:808-10.

8. Hada MS, Samdhani S, Chadha V, Harshvardhan RS, Prakash M. Laryngeal foreign bodies among adults. J Bronchology Interv Pulmonol 2015;22:145-7.

9. Wiseman NE. The diagnosis of foreign body aspiration in childhood. J Pediatr Surg 1984;19:531-5.

10. David AP, Xu MJ, Rosbe KW, Meyer AK, Gesthalter YB, Chan DK. Cryoprobe retrieval of an airway foreign body: a case report and literature review. Int J Pediatr Otorhinolaryngol 2019;125:79-81.

11. Park MW, Baek SK, Jung KY. Laser epilation for unwanted hair in the larynx. Med Lasers 2012;1:31-3.

12. Kim J, Lee YI, Lee JH, Oh SH, Lee SE, Kim YK. Successful treatment of post-operative keloid with combined cryotherapy and ablative fractional CO2 laser. Med Lasers 2020;9:58-61.

13. Jung SY, Hwang NH, Yoon ES, Park SH. Erbium:yttrium aluminum garnet laser treatment for xanthelasma palpebrarum. Med Lasers 2017;6:24-8.

14. Lee SJ, Cho S, Kim YK, Cho SB. Use of a 595-nm pulseddye laser to treat post-procedure ecchymoses. Med Lasers 2014;3:87-9.

15. Kim J, Lee YI, Lee JH, Oh SH, Lee SE, Kim YK. Successful treatment of post-operative keloid with combined cryotherapy and ablative fractional CO2 laser. Med Lasers 2020;9:58-61.

16. Sehgal IS, Dhooria S, Behera D, Agarwal R. Use of cryoprobe for removal of a large tracheobronchial foreign body during flexible bronchoscopy. Lung India 2016;33:543-5.

17. Rafanan AL, Mehta AC. Adult airway foreign body removal. What's new? Clin Chest Med 2001;22:319-30.

18. Lee SJ, Chung PS, Chung SY, Woo SH. Transoral laser excision of a pyriform sinus cyst. Med Lasers 2019;8:84-6.

19. Lee SJ, Chung PS, Chung SY, Woo SH. Respiratory protection for LASER users. Med Lasers 2019;8:43-9.

20. Hong JC, Lee KD. Transoral laser surgery for supraglottic carcinoma. Med Lasers 2013;2:1-7.

21. Cho JG, Park MW, Baek SK, Kwon SY, Jung KY, Woo JS. CO2 laser-induced endotracheal fire. Med Lasers 2013;2:36-9.

How to cite this article: Kim H, Byun G, Lee SJ, Woo $\mathrm{SH}$. Removal of a bronchial foreign body by bronchoscopic cryotherapy: a case study. Med Lasers 2021;10:55-59. https://doi.org/10.25289/ML.2021.10.1.55 